\title{
Chronic Kidney Disease-Associated Pruritus: A Review
}

\author{
Maria Makar Brendan Smyth Frank Brennan \\ Department of Renal Medicine, St. George Hospital, Kogarah, NSW, Australia
}

\section{Keywords}

Chronic kidney disease-associated pruritus - Uraemic pruritus - Chronic kidney disease

\begin{abstract}
Background: Chronic kidney disease-associated pruritus (CKD-aP), also known as uraemic pruritus, is a disabling symptom for patients and a challenging condition for clinicians. Despite being common amongst end-stage kidney disease (ESKD) patients, it remains underestimated and underdiagnosed. The exact pathogenesis remains largely elusive, which hampers the synthesis of a definite treatment approach. Summary: Chronic pruritus (lasting 6 weeks or more in duration) is a common and potentially disabling symptom in patients with advanced CKD. A unified hypothesis of pathogenesis has not yet been concluded. Studies have shown changes in the immunochemical milieu of the skin in patients with CKD-aP with several inciting stimuli identified. However, other unrecognized factors are likely to be involved. This article will review the current observations and understanding of the postulated pathogenesis of CKD-aP, as well as the evidence for current management strategies. Key Messages: CKD-aP is a common and troubling symptom amongst ESKD patients that is associated with decreased quality of life and poor prognosis. Its exact pathogenesis, at
\end{abstract}

karger@karger.com www.karger.com/kbr

Karger"

GOPEN ACCESS
C 2021 The Author(s)

Published by S. Karger AG, Basel

This is an Open Access article licensed under the Creative Commons Attribution-NonCommercial-4.0 International License (CC BY-NC) (http://www.karger.com/Services/OpenAccessLicense), applicable to the online version of the article only. Usage and distribution for commercial purposes requires written permission. the time of writing, is not well-understood. A stepwise approach is recommended for management. Systematic reviews show the largest body of evidence was found for the effectiveness of gabapentin. Comparison is needed between newly emerging pharmacological agents such as kappa-opioid receptor agonists and more established agents, such as the gabapentinoids. Finally, renal transplantation should be considered in severe and refractory cases who are suitable transplant candidates as it has shown an excellent outcome in most cases.

(c) 2021 The Author(s)

Published by S. Karger AG, Basel

\section{Introduction}

Pruritus, or itch, is defined as "an unpleasant sensation associated with a desire to scratch" [1]. Pruritus may be acute or chronic (lasting 6 weeks or more in duration). Chronic pruritus is a common and potentially disabling symptom in patients with advanced chronic kidney disease (CKD), especially in those with end-stage kidney disease (ESKD). In contrast to dermatologic causes of chronic pruritus, it does not present with primary skin alterations, although, over time, secondary skin changes such as excoriations occur as a result of intense scratching [2]. 


\section{Epidemiology}

Worldwide, the prevalence of CKD-associated pruritus (CKD-aP) in haemodialysis (HD) patients ranges from 10 to $77 \%$. Regional differences and the irregular pattern of itch in HD patients may explain why it remains underdiagnosed and underestimated in such patients [3]. A meta-analysis of cross-sectional studies reported an overall prevalence of $\mathrm{CKD}-\mathrm{aP}$ amongst adult dialysis patients of 55\% [4]. In terms of the severity of CKD-aP, the international Dialysis Outcomes and Practice Patterns Study (DOPPS) of 35,452 patients revealed that $18 \%$ of HD patients reported they were troubled by CKD-aP "very much" or "extremely" [5]. That study showed that $\mathrm{CKD}-\mathrm{aP}$ remains largely underestimated, with up to $18 \%$ receiving no treatment and $17 \%$ not reporting itching to health-care staff. Moreover, $69 \%$ of medical directors underestimated the prevalence of pruritus in their unit.

\section{Clinical Characteristics and Natural History}

CKD-aP can present variably. It tends to affect large, discontinuous, but symmetric, areas of skin and to be most symptomatic at night [6]. It does not exhibit a dermatomal pattern and there is no associated primary skin lesion, although over time, there are often signs of chronic scratching [7]. The spatial distribution of CKD-aP varies, and $25-50 \%$ complain of generalized itch [8]. Pruritus is most frequently reported on the legs, back, and scalp [9]. There is no known gender difference. Despite being the most common cause of pruritus in patient with ESKD, it is a clinical truism that not all patients with ESKD experiencing pruritus have CKD-aP. A variety of alternative non-uraemic systemic or dermatologic causes of pruritus should be considered, especially in patients with asymmetric pruritus, other atypical features or in patients with pruritus refractory to therapy [6].

In $\mathrm{CKD}-\mathrm{aP}$, statistically significant associations were found amongst itching severity and health-related quality-of-life domains such as mood, social relations, and sleep [10]. Those with CKD-aP may also be more likely to suffer restless leg syndrome [11]. In addition, patients with severe $\mathrm{CKD}$-aP have a significantly worse prognosis than patients with less severe $\mathrm{CKD}-\mathrm{aP}$, with severe $\mathrm{CKD}-\mathrm{aP}$ being independently associated with mortality even after adjusting for other clinical factors including diabetes mellitus, age, $\beta 2$-microglobulin, and albumin [12].

\section{Pathogenesis}

\section{The Challenge of Unifying Disparate Observations}

The pathophysiology of $\mathrm{CKD}-\mathrm{aP}$ remains unclear. There is no single overarching theory of mechanism. Without that clarity, a coherent approach to management is made more difficult. Currently, our understanding of the pathophysiology derives from multiple disparate sources, with many gaps and some contradictions. These sources include the epidemiological associations between $\mathrm{CKD}-\mathrm{aP}$ and other features of advanced CKD, the multiple isolated observations of disturbance to the immunochemical milieu of the skin in CKD-aP and associated serum biomarkers, and inferences regarding pathophysiology based on our expanding knowledge of basic itch science and the pharmacological action of effective treatments of CKD-aP. These observations, from different fields, will, no doubt, eventually form a part of a unified hypothesis of mechanism. In the next sections, we will address these areas in detail by first summarizing the literature on the conventional associations made with CKD-aP, then synthesizing the diverse descriptions of immunochemical changes in the skin of patients with ESKD and CKD-aP compared to those without CKD-aP, and finally summarizing the evidence of management strategies.

\section{Conventional Associations Revisited}

Over time, conventional wisdom has focused on several purported associations with CKD-aP. A careful examination of these conventions reveals they are not supported by evidence or are inconsistent. In particular, it is often thought that CKD-aP is due to inadequate dialysis. In several large epidemiological studies, dialysis adequacy (as measured by Kt/V) did not consistently correlate with the frequency of CKD-aP $[13,14]$. In addition, the associations between CKD-aP with the levels of serum parathyroid hormone $[15,16]$, serum calcium $[14,17]$, and phosphate $[12,15]$ are inconsistent between different studies. In the DOPPS II, the calcium x phosphate product was correlated with the frequency of CKD-aP but only when that product was at a remarkably high level (i.e., $>80$ $\left.\mathrm{mg}^{2} / \mathrm{dL}^{2}\right)$ [13].

Historically, xerosis has been associated with CKD-aP $[18,19]$. Yosipovitch et al. [20] however did not find an association. Szepietowski et al. [21] have, at least partially, eliminated xerosis as causative of CKD-aP. Xerosis therefore is more likely to be an exacerbating rather than a causative factor. Finally, histamine is commonly considered the principal, if not sole, mediator of itch regardless of cause. 
Fig. 1. Partial representation of hypothesized CKD-aP pathophysiology at the level of the skin. Inciting stimuli for CKD-aP may involve (1) increased calcium ions or $\beta 2$-microglobin deposition but unrecognized factors are likely to be important. Dermal mast cells release tryptase (2), activating PAR-2 receptors which (via sensitization of TRPV1 channels) activates both antegrade and retrograde signalling within the nerve (3). SP is released from nerve endings (4), causing cytokine release from both keratinocytes and dermal mast cells, adding to the pruritogenic environment. This pathway may be further amplified by release of cytokines from Th1 lymphocytes (5). Kappa-opioid receptors are present on multiple actors in this pathway and can dampen activity. Created with BioRender. com. PAR-2, proteinase-activated receptor-2; TRPV1, transient receptor potential vanilloid 1; CKD-aP, chronic kidney disease-associated pruritus; SP, substance P; к-opioid, kappa-opioid.

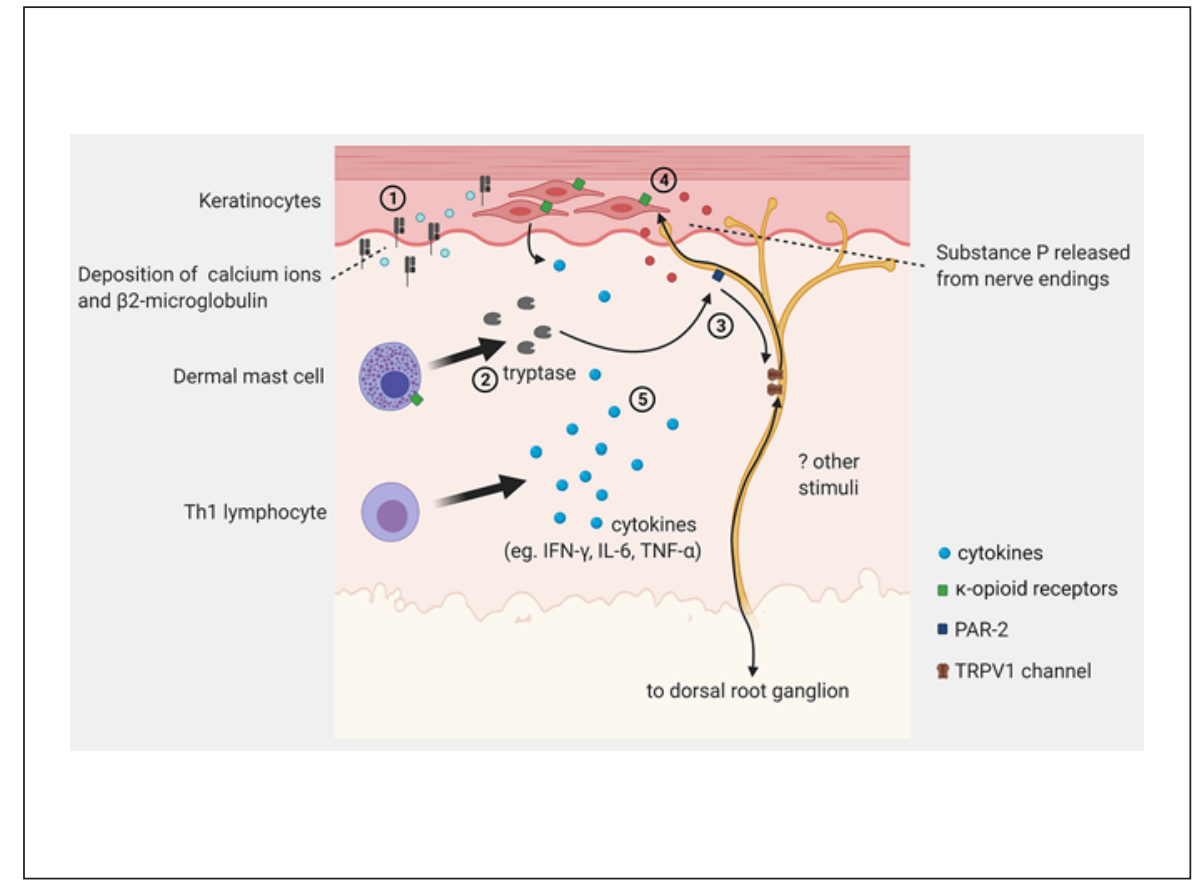

Indeed, antihistamines are routinely prescribed for CKDaP. Modern pruritus science however reveals that the sensation of pruritus is transmitted by dedicated itch fibres, on separate histaminergic and non-histaminergic pathways [22]. Papoiu et al. [23] demonstrated that CKD-aP is transmitted by a non-histaminergic pruritus pathway. Therefore, histamine is unlikely to be causative, and the role for antihistamines in management appears limited.

\section{Towards Pathogenesis}

Our current understanding of the pathogenesis of $\mathrm{CKD}$-aP currently relies on studies comparing the immunochemical milieu of the skin in patients with ESKD with CKD-aP with those without CKD-aP. The observed differences are then aligned with the known actions of the differing substances or cells, which are often gleaned from general pruritus research (i.e., without the confounding factor of CKD). As such, important assumptions must be made to infer causation. With this limitation in mind, we know the following:

- In CKD-aP, there is an increase in dermal mast cells [24] and dermal cell tryptase [25].

- Tryptase activates proteinase-activated receptor-2 (PAR-2) on itch nerve afferent fibres [26].

- The activation of PAR-2 sensitises the transient receptor potential vanilloid 1 (TRPV1) ion channels (a target of capsaicin) downstream in nerve afferents and the transmission of an itch signal to the dorsal root ganglion and onto the dorsal horn in the spinal cord [27].

- The sensitisation of TRPV1 causes the retrograde release of substance P (SP) from nerve endings. SP, in turn, activates dermal mast cells and keratinocytes to release more cytokines.

- In the skin of patients with $\mathrm{CKD}-\mathrm{aP}$, there is an upregulation of kappa-opioid receptors and that increase is statistically correlated with the severity of CKD-aP [28].

- The activation of kappa-opioid receptors has an antipruritic effect. These receptors appear on the surface of dermal mast cells, keratinocytes, and in the dorsal horn.

- In CKD-aP, there is a significant shift in expression of uncommitted Th lymphocytes to Th1 lymphocytes [29].

- In CKD-aP, there is an increase in the cytokines produced by Th1 lymphocytes including interferon- $\gamma$ (IFN- $\gamma$ ), interleukin-6 (IL-6), and tumour necrosis factor- $\alpha$ (TNF- $\alpha)$ [29].

- TNF- $\alpha$ enhances the expression of Th1 lymphocytes.

- IL-6 sets off a cascade known as the IL-6/pBRK/p-ERK signalling-induced pruritus [30].

- In CKD-aP, there is an increase in interleukin-31 (IL31), a Th2 lymphocyte pruritogenic cytokine $[31,32]$. 
Table 1. Medications and interventions used in the management of CKD-aP and their known or proposed mechanism of action

\begin{tabular}{|c|c|}
\hline Moisturisers & Helps restore skin permeability barrier \\
\hline Gabapentin/pregabalin & $\begin{array}{l}\text { Uncertain. Likely inhibition of } a 2 \delta \text { subunit of calcium channels at the dorsal horn }[34,35] \text {. Despite their name, do not act on } \\
\text { GABA receptors [36] }\end{array}$ \\
\hline Kappa-Opioid agonists & $\begin{array}{l}\text { Activation of kappa-opioid receptors has an antipruritic effect. Peripherally, kappa-opioid receptors are on the surface of dermal } \\
\text { mast cells and keratinocytes, and centrally in the dorsal horn. The efficacy of a peripherally acting kappa-opioid agonist, } \\
\text { indicates the mechanism of action in CKD-aP, is peripheral [37] }\end{array}$ \\
\hline Capsaicin & Acts on TRPV1 channels on nerve afferents to denude SP, an important neurotransmitter in pruritus $[38,39]$ \\
\hline $\begin{array}{l}\text { Evening primrose oil } \\
\text { (active constituent: } \\
\text { gamma linolenic acid) }\end{array}$ & $\begin{array}{l}\text { Supplements the early part of the omega- } 6 \text { essential fatty acid cascade in the epidermis. This reduces production of arachidonic } \\
\text { acid, leading, in turn, to a reduced production of pro-inflammatory cytokines leukotriene B4 and prostaglandin E2 [40, 41]. In } \\
\text { murine studies, evening primrose oil reduces the levels of serum IL- } 6 \text { and TNF- } \alpha\end{array}$ \\
\hline Sertraline & $\begin{array}{l}\text { Selective serotonin reuptake inhibitor. Enhances the natural inhibitory pathway for itch. Also, reduces circulating levels of IL-6 } \\
\text { and TNF- } \alpha \text { [42] }\end{array}$ \\
\hline Mirtazapine & Blocks certain adrenergic and serotonin receptors and histamine 1 receptors \\
\hline Thalidomide & $\begin{array}{l}\text { Reduces TNF- } \alpha \text {, leading to a reduction in Th1 lymphocyte expression } \\
\text { Reduces the synthesis of IL- } 6 \text { [43] }\end{array}$ \\
\hline UVB therapy & Apoptosis of keratinocytes and dermal mast cells [44]. Decreased expression of Th1 lymphocytes \\
\hline Phytocannabinoids & $\begin{array}{l}\text { The activation of endogenous cannabinoid receptors (CB1 and CB2) may have an antipruritic effect, in part mediated via action } \\
\text { at TRPV1 receptors }\end{array}$ \\
\hline
\end{tabular}

CKD-aP, chronic kidney disease-associated pruritus; TRPV1, transient receptor potential vanilloid 1; SP, substance P; GABA, gamma-aminobutyric acid; UVB, ultraviolet B.

- There is indirect evidence that leukotriene B4, a highly pruritogenic cytokine, is involved in CKD-aP [33].

- In patients with ESKD, there is an increased concentration of $\beta 2$-microglobin in the serum and skin [12, 34]. $\beta 2$-microglobin is pruritogenic [35].

- In CKD-aP patients, there is an increased level of extracellular free calcium ions in the basal layer of the epidermis compared to ESKD patients without CKD$\mathrm{aP}$ [36].

This complex pathophysiology is summarized, in part, in Figure 1. Much remains to be explained, but our current understanding emphasizes the role of crosstalk between dermal mast cells, epidermal keratinocytes, Th-1 lymphocytes, and nerve fibres.

In contrast to the peripheral mechanisms, little information is available concerning the central pathways involved in transmission of pruritus in patients with kidney disease. The pathophysiology of CKD-aP may extend to the CNS, with a functional CNS imaging study finding different areas of activity in patients with ESKD and healthy controls exposed to a pruritogenic stimulus [23]. In addition to its expression on keratinocytes, kappa-opioid receptors are widely expressed in the CNS [37]. The relative importance of central versus peripheral kappaopioid receptors in the pathophysiology of CKD-aP remains unclear. While the 2 kappa agonists with demonstrated efficacy (nalfurafine and difelikefalin) have limited CNS penetration, it may be that some central action does contribute to their effect. Overall, the exact CNS pathways mediating $\mathrm{CKD}-\mathrm{aP}$ remain to be elucidated.

The next section summarises the management of CKD-aP. To assist readers in linking the above elements of pathogenesis with management, Table 1 lists each therapy and intervention with its proposed mechanism of action.

\section{Measurement of CKD-aP}

CKD-aP is most commonly measured on a numeric rating scale from 0 to 10 , as is found in multidimensional symptom scoring tools such as the Edmonton Symptom Assessment System revised: Renal. Other tools include a visual analogue scale (where the itch intensity is indicated on a continuous line from 0 to 10), a 5-point Likert scale (as in the Integrated Patient Outcome Scale [Renal][IP- 
OS-Renal]), and multidimensional scores such as Duo or 5 -D itch scale, which permit description of itch frequency and distribution in addition to severity. Although the multidimensional tools are validated in a general pruritus population [38], these instruments are not well validated in the CKD population. Information on minimal clinically important differences is sparse in both the general and CKD population. This must be borne in mind when comparing results between studies.

\section{Management}

The optimal management for $\mathrm{CKD}-\mathrm{aP}$ is not yet welldefined. At least in part, this reflects the lack of clear pathogenic mechanisms, as discussed. Several reviews have recommended a stepwise approach to management depending on patient's response to initial therapy [32, 39].

\section{Initial Management Strategies}

Topical Emollients

Given the high incidence of xerosis in patients with $\mathrm{CKD}-\mathrm{aP}$, regular skin care is important for alleviating pruritus. A randomized, double-blind intraindividual (left vs. right comparison), multicentre clinical study followed by an open-labelled use of the test product on all of the xerotic areas, showed that the use of glycerol and paraffin containing emulsion compared to emulsion alone is highly effective in patients with moderate-to-severe uraemic xerosis with a substantial improvement of the uraemic pruritus (75\% of patients) and quality of life at study end [40]. In another study, the regular use of an aqueous gel with higher water content was shown to reduce itching and improve xerosis in patients with mild uraemic pruritus [41].

\section{Specific Topical Agents}

For CKD-aP not responding to initial management, topical agents could be trialed as a next step. The following topical agents have been studied for efficacy in managing CKD-aP:

\section{Topical Capsaicin}

A randomized, double-blinded, crossover placebocontrolled trial of capsaicin $0.03 \%$ showed a significant reduction in the mean pruritus score on weeks 1-4 of capsaicin treatment $(p<0.001)$ compared to placebo [42]. Other preceding trials were criticized for design flaws and insufficiency of data that hindered their evaluation [43].
The main clinical difficulty with capsaicin is that its topical application is invariably followed by a transient burning sensation which many patients find intolerable.

\section{Topical Pramoxine}

A randomized, double-blind, controlled comparative trial, where topical $1 \%$ pramoxine was applied twice daily for 4 weeks compared to an emollient, showed a $61 \%$ decrease in itch intensity in the treatment group versus $12 \%$ reduction in the control group [44]. Pramoxine is a topi$\mathrm{cal}$ anaesthetic which decreases the permeability of neuronal membranes to sodium ions, blocking both the initiation and conduction of nerve impulses.

\section{Topical Cromolyn Sodium}

Cromolyn sodium is a mast cell membrane stabiliser which was initially reported as an effective oral therapy in 2 patients with refractory $\mathrm{CKD}-\mathrm{aP}$ [45]. A randomized, double-blind, prospective, 4-week study of $60 \mathrm{HD}$ patients showed a significant reduction in CKD-aP in favour of topical cromolyn sodium $4 \%(p<0.04)$ compared to placebo at the end of week 4 [46].

\section{Topical Gamma-Linolenic Acid}

One randomized, double-blind, placebo-controlled, crossover study showed the efficacy of a gamma-linolenic acid (GLA)-rich cream, which was statistically significant compared to placebo cream for alleviating CKD-aP [47].

\section{Topical Sericin}

One randomised, double-blind, placebo-controlled study showed a significant improvement in itching and quality of life in the group treated by sericin compared to placebo. Sericin possibly works by suppressing the release of pro-inflammatory cytokines [48].

\section{Topical Vitamin D}

One open-label pilot study that assessed the efficacy and safety of topical vitamin $\mathrm{D}$ on 23 patients with CKDaP showed skin dryness and itching were significantly decreased after 2 and 4 weeks of the topical vitamin D treatment compared with the vehicle $(p<0.05)$ [49].

\section{Other Agents}

Several other topical agents, targeting specific receptors, have been used or proposed. Cold receptor agonists, such as menthol (activating cold receptors in the skin has an antipruritic effect) [50] and topical cannabinoids (activating endocannabinoid receptors in the skin has an antipruritic effect) [51]. Lack of efficacy was demonstrated 
for the following agents in regard to management of CKD-aP: topical calcineurin inhibitors tacrolimus $0.1 \%$ [52] and pimecrolimus $1 \%$ [53], and dead sea mineralenriched body lotion [54].

\section{Systemic Agents}

For patients with resistant $\mathrm{CKD}-\mathrm{aP}$, not rapidly responding to initial management and specific topical agents, therapy should then be escalated to systemic pharmacologic agents.

\section{Gabapentin and Pregabalin}

Both gabapentinoids have been used in the management of CKD-aP. Multiple double-blind placebo-controlled trials have shown a statistically significant benefit of gabapentin compared to placebo in the management of CKD-aP and a recent meta-analysis found these agents to be effective (mean reduction in the itch score compared with placebo of $4.95,95 \%$ confidence interval [CI] 4.44-5.46; based on 5 trials including 297 participants) and safe [55]. A starting dose of $100 \mathrm{mg}$ gabapentin or 25 $\mathrm{mg}$ pregabalin in the evening is recommended to minimize adverse events in this population [56]. Both drugs are dialysable, and severe toxicity can be managed with dialysis [57]. In usual practice, supplemental doses postdialysis are rarely required.

Few studies have compared gabapentinoids to other active agents. A randomised single-blind clinical trial comparing pregabalin (50 mg every other day) versus doxepin (10 mg daily) showed pregabalin to be more effective than doxepin in reducing the severity of CKD-aP and improving the quality of life of patients [58]. A 12week randomized, double-blind, placebo-controlled study that included $179 \mathrm{HD}$ patients compared pregabalin (75 mg twice per week) versus ondansetron ( $8 \mathrm{mg}$ daily) or placebo, showed pregabalin to be superior [59], which is consistent with meta-analysis of 3 randomised studies showing ondansetron to be equivalent to placebo in the treatment of CKD-aP [55].

There is no evidence to suggest that one gabapentinoid should be preferred to another. A 14-week randomised, prospective, crossover trial of HD patients who were randomly assigned to receive gabapentin $(300 \mathrm{mg}$ post HD) or pregabalin (75 mg daily) showed both gabapentin and pregabalin improved pruritus significantly with no difference in their efficacy [60]. Another study used gabapentin (starting dose $100 \mathrm{mg}$ after dialysis or daily) or pregabalin (starting dose $25 \mathrm{mg}$ after dialysis or daily) in 71 consecutive patients with CKD-aP. Patients' intolerant of gabapentin were offered pregabalin. In to- tal, gabapentin or pregabalin relieved itching in $85 \%$ of patients [61].

\section{Kappa-Opioid Agonists}

The studies of the kappa-opioid agonists have consistently shown statistically significant efficacy in the management of CKD-aP although the magnitude of this effect (mean reduction in the itch score compared with placebo of $1.05,95 \%$ CI $0.70-1.40$; based on 5 trials including 661 participants) may be less than observed with gabapentinoids [55]. Difelikefalin is a peripherally specific, highly selective agonist of kappa-opioid receptors. A recent phase 3 clinical trial for $\mathrm{CKD}-\mathrm{aP}$ in $\mathrm{HD}$ patients showed a significant reduction in itch intensity and improved itch-related quality of life in patients treated with difelikefalin compared to placebo [62]. Nalfurafine, a kappa-opioid agonist has been studied in 2 multicentre, randomized, double-blind, placebo-controlled studies of patients with CKD-aP, who were randomized to receive post-dialysis intravenous treatment with either nalfurafine or placebo for 2-4 weeks. Statistically significant reductions in $\mathrm{CKD}-\mathrm{aP}$ were found in favour of nalfurafine compared to placebo $[63,64]$. Studies comparing these agents to gabapentinoids are lacking.

\section{$\mathrm{Mu}-$ Receptor Antagonists}

While kappa-opioid agonists have an antipruritic effect, the activation of mu-opioid receptors has, especially in the dorsal horn, a pruritic effect. Naltrexone is a muopioid antagonist. The studies on the efficacy of naloxone in CKD-aP are inconsistent and it is not recommended $[55,65,66]$.

\section{Antihistamines}

As stated above, CKD-aP is not histaminergic in origin. Nevertheless, antihistamines are used commonly. Studies on antihistamines have shown no or modest benefit [67] or are flawed methodologically $[55,68]$. We do not recommend antihistamines in the management of CKD-aP.

\section{Sertraline}

There have been 3 studies on the use of sertraline in CKD-aP. They varied in methodology: an open-label trial [69], a retrospective cohort study [70], and a doubleblind, placebo-controlled trial [71]. The latter demonstrated a significantly lower itch score with sertraline but was limited by uncertainties in methodology $[55,71]$. 
Fig. 2. Stepwise approach to the management of CKD-aP guided by severity and/or resistance of pruritus. A stepwise approach is recommended in the management of CKD-aP. Initial management strategies including moisturisers and other topical agents should be trialed first. Low-dose gabapentinoids should be considered as an initial systemic agent for patients with resistant CKD-aP. In refractory cases, other agents, such as kappa-opioid receptor agonists, sertraline, and UVB therapy are recommended. UVB, ultraviolet B; CKD-aP, chronic kidney disease-associated pruritus; kappa-opioid, kappa-opioid.

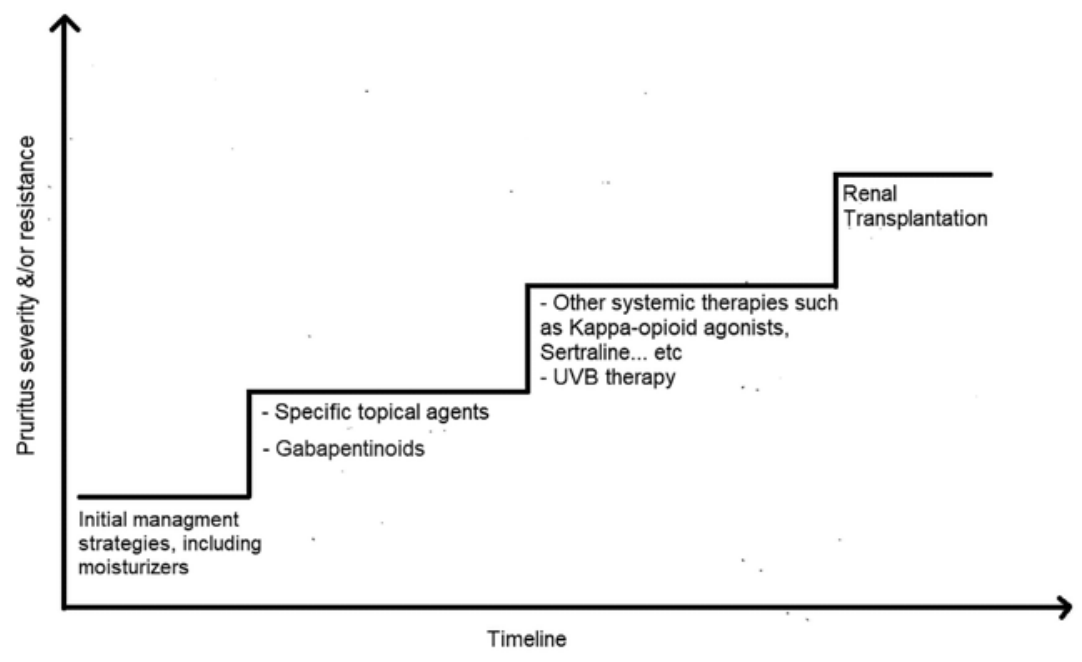

\section{Mast Cell Stabilisers}

Oral cromolyn sodium (135 mg 3 times daily) [72] and oral zinc sulphate $(440 \mathrm{mg} /$ day) [73] were shown to be more effective than placebo in relieving CKD-aP. Oral nicotinamide however was no more effective than placebo [74].

\section{Gamma-Linolenic Acid}

This is a constituent of evening primrose oil. The efficacy of oral GLA was studied in a randomized trial, where the control was linolenic acid. GLA-rich evening primrose oil improved overall skin symptoms, including pruritus, significantly compared to those who received linolenic acid alone $(p<0.05)$ [75].

\section{Montelukast}

Montelukast is a leukotriene receptor antagonist. Two randomized placebo-controlled trials have shown montelukast to be significantly more effective than placebo in alleviating CKD-aP $[76,77]$.

\section{Thalidomide}

There is one double-blind, placebo-controlled RCT on the use of thalidomide in CKD-aP that showed statistically significant benefit [78].

\section{Turmeric}

A single study, randomizing 100 participants to 3 turmeric capsules daily or placebo found a significant improvement in itch with turmeric (mean difference [on a 40-point scale] $6.4,95 \%$ CI 5.4-7.4) [79].

Chronic Kidney Disease-Associated Pruritus: A Review
Other Agents

Several other agents have shown promise, including aprepitant (an antagonist of neurokinin-1 receptor, which mediates SP signalling) [80], mirtazapine [81], and parenteral lidocaine [82].

\section{Phototherapy}

Ultraviolet B (UVB) irradiation has been shown to be effective in a number of trials and should be considered in patients with refractory $\mathrm{CKD}-\mathrm{aP}$ [83-86]. A relatively small total dose of $2.11 \mathrm{~J} / \mathrm{cm}^{2}$ proved effective in the majority of treated patients [83]. Durability of treatment has been variable. Remissions were reported to be long-lasting in many patients, sometimes $>2$ years [84]; however, for other patients, recurrence of symptoms following cessation of therapy may be a problem [85]. By contrast, UVA light was shown to have no significant effect and is not recommended in the treatment of CKD-aP [86].

\section{Alteration of Dialytic Treatment}

There is evidence from randomized studies to suggest that high-flux HD is superior to low-flux for CKD-aP [87] and that haemodiafiltration may be superior to high-flux HD [88]. The addition of haemoperfusion may also provide additional benefit [89]. Methodological flaws limit the strength of these observations but further study is warranted.

\section{Renal Transplantation}

In very severe and refractory cases, patients suitable for renal transplantation might be switched to "high ur- 
gency" status, as successful renal transplantation dramatically reduces the prevalence of CKD-aP $[39,90]$. This fact implies that the pathology underlying CKD-aP is at least partly reversible.

\section{Other Therapies with Inconclusive Results}

Studies of acupuncture [91, 92], ondansetron [93-95], and cholestyramine $[96,97]$ have been inconclusive and they do not presently have a role in the management of CKD-aP.

\section{Evidence Summary}

In their recent Cochrane systematic review, Hercz et al. [55] conclude that gabapentinoids are the most wellstudied treatment and demonstrate the largest relative effect size, that kappa-opioid agonists are likely to have a modest effect, and that oral montelukast, turmeric, zinc sulphate, and topical capsaicin may also be effective. This review is notable for identifying a large number of small, heterogeneous studies, many of which were methodologically flawed, permitting few firm conclusions to be made about many potential therapies.

\section{Clinical Recommendations}

Several authors have published recommended treatment algorithms for CKD-aP [32, 39]. Similarly, we recommend a stepwise approach to management (see Fig. 2). First, before assuming that the cause of pruritus in a patient with $\mathrm{CKD}$ is $\mathrm{CKD}-\mathrm{aP}$, always consider other non-uraemic causes. Having concluded that the patient has CKD-aP, the initial management is topical moisturisers and gabapentinoids. Patients should be advised about side effects of the latter (e.g., dizziness, ataxia, and somnolence) and these medications should be initiated at low doses. For dialysis patients, commence gabapentin $100 \mathrm{mg}$ or pregabalin $25 \mathrm{mg}$ post-dialysis. For those ESKD patients on a conservative, non-dialysis pathway, commence gabapentin $100 \mathrm{mg}$ or pregabalin $25 \mathrm{mg}$ every alternate night. Patients' intolerant of one may tolerate the other and a legitimate strategy is to rotate the gabapentinoids. It should also be noted that the gabapentinoids have efficacy in the management of two other symptoms commonly experienced by patients with ESKD - uraemic restless legs syndrome [98] and painful peripheral neuropathy [99] and that this one class of medicine may be used to simultaneously manage several symptoms. In refractory cases, other agents, such as kappa-opioid receptor agonists and UVB therapy are recommended. Regarding the kappa-opioid agonists, longer term safety and efficacy data, as well as comparative ef- ficacy data with other medications such as the gabapentinoids, are needed.

\section{Future}

CKD-aP remains a challenging issue for both patients and physicians. Greater understanding of pathogenesis is crucial and will, no doubt, build upon the significant advances in the general pathophysiology of pruritus and assist in more targeted management. A large number of treatments have been considered for CKD-aP, with highly variable results. Comparison is needed between newly emerging pharmacological agents such as kappa-opioid receptor agonists and more established agents, such as the gabapentinoids.

\section{Conclusion}

CKD-aP is a common and troubling symptom amongst ESKD patients that is associated with decreased quality of life, sleep impairment, and poor prognosis. Its exact pathogenesis is not well-understood. A stepwise approach is recommended for management starting with topical agents then escalating to gabapentinoids for resistant pruritus. Systematic reviews highlight the uncertainty about the effect of other therapies. A trial of kappaopioid receptor agonists, if available, or UVB phototherapy should then be considered in refractory cases. Multiple other therapeutic strategies have been tested and could be considered. Finally, renal transplantation should be considered in severe and refractory cases who are suitable transplant candidates as it has shown an excellent outcome in most cases.

\section{Conflict of Interest Statement}

There are no conflicts of interest to declare.

\section{Funding Sources}

This study did not receive any funding.

\section{Author Contributions}

The review was conceived by B.S., with research and manuscript drafting by M.M., and expert input from F.B. All authors collaborated on the writing of the manuscript. 


\section{References}

1 Rothman S. Physiology of itching. Physiol Rev. 1941;21(2):357-81.

2 Kremer AE, Mettang T. [Pruritus in systemic diseases: common and rare etiologies]. Internist. 2019;60(8):814-20.

3 Weisshaar E. Epidemiology of uraemic itch: new data. Eur J Pain. 2016;20(1):32-6.

$4 \mathrm{Hu}$ X, Sang Y, Yang M, Chen X, Tang W. Prevalence of chronic kidney disease-associated pruritus among adult dialysis patients: a meta-analysis of cross-sectional studies. Medicine. 2018;97(21):e10633.

5 Rayner HC, Larkina M, Wang M, GrahamBrown M, van der Veer SN, Ecder T, et al. International comparisons of prevalence, awareness, and treatment of pruritus in people on hemodialysis. Clin J Am Soc Nephrol. 2017;12(12):2000-7.

6 Combs SA, Teixeira JP, Germain MJ. Pruritus in kidney disease. Semin Nephrol. 2015;35(4): 383-91.

7 Simonsen E, Komenda P, Lerner B, Askin N, Bohm C, Shaw J, et al. Treatment of uremic pruritus: a systematic review. Am J Kidney Dis. 2017;70(5):638-55.

8 Ponticelli C, Bencini PL. Uremic pruritus: a review. Nephron. 1992;60(1):1-5.

9 Weiss M, Mettang T, Tschulena U, PasslickDeetjen J, Weisshaar E. Prevalence of chronic itch and associated factors in haemodialysis patients: a Representative Cross-Sectional study. Acta Derm Venereol. 2015;95(7):81621.

10 Mathur VS, Lindberg J, Germain M, Block G, Tumlin J, Smith M, et al. A longitudinal study of uremic pruritus in hemodialysis patients. Clin J Am Soc Nephrol. 2010;5(8):1410-9.

11 Castillo-Torres SA, Ibarra-Sifuentes HR, Sánchez-Terán H, Sánchez-Martínez C, ChávezLuévanos B, Estrada-Bellmann I. Restless legs syndrome in end-stage renal disease patients undergoing hemodialysis. Arq Neuropsiquiatr. 2018;76(12):827-30.

12 Narita I, Alchi B, Omori K, Sato F, Ajiro J, Saga D, et al. Etiology and prognostic significance of severe uremic pruritus in chronic hemodialysis patients. Kidney Int. 2006;69(9) 1626-32.

13 Pisoni RL, Wikström B, Elder SJ, Akizawa T, Asano Y, Keen ML, et al. Pruritus in haemodialysis patients: international results from the Dialysis Outcomes and Practice Patterns Study (DOPPS). Nephrol Dial Transplant. 2006;21(12):3495-505.

14 Duque MI, Thevarajah S, Chan YH, Tuttle $\mathrm{AB}$, Freedman BI, Yosipovitch G. Uremic pruritus is associated with higher kt/V and serum calcium concentration. Clin Nephrol. 2006;66(3):184-91.

15 Shirazian S, Kline M, Sakhiya V, Schanler M, Moledina D, Patel C, et al. Longitudinal predictors of uremic pruritus. J Ren Nutr. 2013; 23(6):428-31.

16 Makhlough A, Emadi N, Sedighi O, Khademloo M, Bicmohamadi AR. Relationship be- tween serum intact parathyroid hormone and pruritus in hemodialysis patients. Iran J Kidney Dis. 2013;7(1):42-6.

17 Mettang T, Matterne U, Roth HJ, Weisshaar E. Lacking evidence for calcium-binding protein fetuin-A to be linked with chronic kidney disease-related pruritus (CKD-rP). NDT Plus. 2010;3(1):104-5.

18 Morton CA, Lafferty M, Hau C, Henderson I, Jones M, Lowe JG. Pruritus and skin hydration during dialysis. Nephrol Dial Transplant. 1996;11(10):2031-6.

19 Chorą̇̇yczewska W, Reich A, Szepietowski JC. Lipid content and barrier function analysis in uraemic pruritus. Acta Derm Venereol. 2016;96(3):402-3.

20 Yosipovitch G, Duque MI, Patel TS, Ishiuji Y, Guzman-Sanchez DA, Dawn AG, et al. Skin barrier structure and function and their relationship to pruritus in end-stage renal disease. Nephrol Dial Transplant. 2007;22(11):3268-72.

21 Szepietowski JC, Reich A, Schwartz RA. Uraemic xerosis. Nephrol Dial Transplant. 2004; 19(11):2709-12.

22 Davidson S, Zhang X, Yoon $\mathrm{CH}$, Khasabov SG, Simone DA, Giesler GJ Jr. The itch-producing agents histamine and cowhage activate separate populations of primate spinothalamic tract neurons. J Neurosci. 2007; 27(37):10007-14

23 Papoiu AD, Emerson NM, Patel TS, Kraft RA, Valdes-Rodriguez R, Nattkemper LA, et al. Voxel-based morphometry and arterial spin labeling fMRI reveal neuropathic and neuroplastic features of brain processing of itch in end-stage renal disease. J Neurophysiol. 2014; 112(7):1729-38.

24 Leong SO, Tan CC, Lye WC, Lee EJ, Chan HL. Dermal mast cell density and pruritus in endstage renal failure. Ann Acad Med Singap. 1994;23(3):327-9.

25 Szepietowski J, Thepen T, van Vloten WA, Szepietowski T, Bihari IC. Pruritus and mast cell proliferation in the skin of haemodialysis patients. Inflamm Res. 1995;44 Suppl 1:S84-5.

26 Steinhoff M, Neisius U, Ikoma A, Fartasch M, Heyer G, Skov PS, et al. Proteinase-activated receptor-2 mediates itch: a novel pathway for pruritus in human skin. J Neurosci. 2003; 23(15):6176-80.

27 Xie B, Li XY. Inflammatory mediators causing cutaneous chronic itch in some diseases via transient receptor potential channel subfamily $\mathrm{V}$ member 1 and subfamily A member 1. J Dermatol. 2019;46(3):177-85.

28 Wieczorek A, Krajewski P, Kozioł-Gałczyńska M, Szepietowski JC. Opioid receptors expression in the skin of haemodialysis patients suffering from uraemic pruritus. J Eur Acad Dermatol Venereol. 2020;34(10):2368-72.

29 Kimmel M, Alscher DM, Dunst R, Braun N, Machleidt C, Kiefer T, et al. The role of microinflammation in the pathogenesis of uraemic pruritus in haemodialysis patients. Nephrol Dial Transplant. 2006;21(3):749-55.
30 Keshari S, Sipayung AD, Hsieh CC, Su LJ, Chiang YR, Chang HC, et al. IL-6/p-BTK/p-ERK signaling mediates calcium phosphate-induced pruritus. FASEB J. 2019;33(11):12036-46.

31 Ko MJ, Peng YS, Chen HY, Hsu SP, Pai MF, Yang JY, et al. Interleukin-31 is associated with uremic pruritus in patients receiving hemodialysis. J Am Acad Dermatol. 2014;71(6) 1151-9.e1.

32 Reszke R, Szepietowski JC. End-stage renal disease chronic itch and its management. Dermatol Clin. 2018;36(3):277-92.

33 Li S, Andoh T, Zhang Q, Uta D, Kuraishi Y. $\beta 2-$ Microglobulin, interleukin-31, and arachidonic acid metabolites (leukotriene $\mathrm{B}(4)$ and thromboxane $\mathrm{A}(2)$ ) are involved in chronic renal failure-associated itch-associated responses in mice. Eur J Pharmacol. 2019; 847:19-25.

34 Assounga AG, Bascoul S, Canaud B, Bouya PA, Vendrell JP, Sciolla JP, et al. A study of beta 2-microglobulin skin deposits in dialyzed patients and healthy controls. Am J Kidney Dis. 1990;15(6):556-61.

35 Andoh T, Maki T, Li S, Uta D. $\beta 2$ Microglobulin elicits itch-related responses in mice through the direct activation of primary afferent neurons expressing transient receptor potential vanilloid 1. Eur J Pharmacol. 2017;810:134-40.

36 Momose A, Shiraiwa Y, Narita S, Kusumi T, Goto S, Sera K. Total calcium and albumin are decreased in the deeper epidermis of patients with chronic kidney disease-associated pruritus. Nephron. 2017;136(2):103-10.

37 Uhlén M, Fagerberg L, Hallström BM, Lindskog C, Oksvold P, Mardinoglu A, et al. Proteomics. Tissue-based map of the human proteome. Science. 2015;347(6220): 1260419.

38 Reich A, Heisig M, Phan NQ, Taneda K, Takamori K, Takeuchi S, et al. Visual analogue scale: evaluation of the instrument for the assessment of pruritus. Acta Derm Venereol. 2012;92(5):497-501.

39 Mettang T. Uremic itch management. In: Szepietowski J, Weisshaar E, editors. Itch: management in clinical practice. Basel: Karger; 2016. p. 133-41.

40 Balaskas E, Szepietowski JC, Bessis D, Ioannides D, Ponticelli C, Ghienne C, et al. Randomized, double-blind study with glycerol and paraffin in uremic xerosis. Clin J Am Soc Nephrol. 2011;6(4):748-52.

41 Okada K, Matsumoto K. Effect of skin care with an emollient containing a high water content on mild uremic pruritus. Ther Apher Dial. 2004;8(5):419-22.

42 Makhlough A, Ala S, Haj-Heydari Z, Kashi Z, Bari A. Topical capsaicin therapy for uremic pruritus in patients on hemodialysis. Iran J Kidney Dis. 2010;4(2):137-40.

43 Gooding SM, Canter PH, Coelho HF, Boddy K, Ernst E. Systematic review of topical capsaicin in the treatment of pruritus. Int J Dermatol. 2010;49(8):858-65. 
44 Young TA, Patel TS, Camacho F, Clark A, Freedman BI, Kaur M, et al. A pramoxinebased anti-itch lotion is more effective than a control lotion for the treatment of uremic pruritus in adult hemodialysis patients. J Dermatolog Treat. 2009;20(2):76-81.

45 Rosner MH. Cromolyn sodium: a potential therapy for uremic pruritus? Hemodial Int. 2006;10(2):189-92.

46 Feily A, Dormanesh B, Ghorbani AR, Moosavi Z, Kouchak M, Cheraghian B, et al. Efficacy of topical cromolyn sodium $4 \%$ on pruritus in uremic nephrogenic patients: a randomized double-blind study in 60 patients. Int I Clin Pharmacol Ther. 2012;50(7):510-3.

47 Chen YC, Chiu WT, Wu MS. Therapeutic effect of topical gamma-linolenic acid on refractory uremic pruritus. Am J Kidney Dis. 2006;48(1):69-76.

48 Aramwit $\mathrm{P}$, Keongamaroon $\mathrm{O}$, Siritientong T, Bang N, Supasyndh O. Sericin cream reduces pruritus in hemodialysis patients: a randomized, double-blind, placebo-controlled experimental study. BMC Nephrol. 2012;13:119.

49 Jung KE, Woo YR, Lee JS, Shin JH, Jeong JU, Koo DW, et al. Effect of topical vitamin D on chronic kidney disease-associated pruritus: an open-label pilot study. J Dermatol. 2015; 42(8):800-3.

50 Yosipovitch G, Szolar C, Hui XY, Maibach H Effect of topically applied menthol on thermal, pain and itch sensations and biophysical properties of the skin. Arch Dermatol Res. 1996;288(5-6):245-8.

51 Szepietowski JC, Reich A, Szepietowski T. Emollients with endocannabinoids in the treatment of uremic pruritus: discussion of the therapeutic options. Ther Apher Dial. 2005;9(3):277-9.

52 Duque MI, Yosipovitch G, Fleischer AB Jr, Willard J, Freedman BI. Lack of efficacy of tacrolimus ointment $0.1 \%$ for treatment of hemodialysis-related pruritus: a randomized, double-blind, vehicle-controlled study. J Am Acad Dermatol. 2005;52 (3 Pt 1):519-21.

53 Ghorbani AR, Feily A, Khalili A, Dormanesh B. Lack of efficacy of topical calcineurin inhibitor pimecrolimus $1 \%$ on pruritus of severely uremic patients: a randomized doubleblind study in 60 patients. Dermatitis. 2011; 22(3):167-8.

54 Boaz M, Shtendik L, Oron M, Portugal-Cohen M, Kohen R, Biro A, et al. A randomized controlled clinical trial comparing the efficacy of dead sea mineral-enriched body lotion versus two types of placebo in the treatment of cutaneous dryness, itching, peeling and tightness in hemodialysis patients (EDIT). Nephron Clin Pract. 2009;113(3):c169-76.

55 Hercz D, Jiang SH, Webster AC. Interventions for itch in people with advanced chronic kidney disease. Cochrane Database Syst Rev. 2020;12(12):Cd011393.

56 Lau T, Leung S, Lau W. Gabapentin for uremic pruritus in hemodialysis patients: a qualitative systematic review. Can J Kidney Health Dis. 2016;3:14.
57 Yoo L, Matalon D, Hoffman RS, Goldfarb DS Treatment of pregabalin toxicity by hemodialysis in a patient with kidney failure. Am J Kidney Dis. 2009;54(6):1127-30.

58 Foroutan N, Etminan A, Nikvarz N, Shojai Shahrokh Abadi M. Comparison of pregabalin with doxepin in the management of uremic pruritus: a randomized single blind clinical trial. Hemodial Int. 2017;21(1):63-71.

59 Yue J, Jiao S, Xiao Y, Ren W, Zhao T, Meng J. Comparison of pregabalin with ondansetron in treatment of uraemic pruritus in dialysis patients: a prospective, randomized, doubleblind study. Int Urol Nephrol. 2015;47(1): 161-7.

60 Solak Y, Biyik Z, Atalay H, Gaipov A, Guney F, Turk S, et al. Pregabalin versus gabapentin in the treatment of neuropathic pruritus in maintenance haemodialysis patients: a prospective, crossover study. Nephrology. 2012; 17(8):710-7.

61 Rayner H, Baharani J, Smith S, Suresh V, Dasgupta I. Uraemic pruritus: relief of itching by gabapentin and pregabalin. Nephron Clin Pract. 2012;122(3-4):75-9.

62 Fishbane S, Jamal A, Munera C, Wen W, Menzaghi F. A phase 3 trial of difelikefalin in hemodialysis patients with pruritus. $\mathrm{N}$ Engl J Med. 2020;382(3):222-32.

63 Wikström B, Gellert R, Ladefoged SD, Danda Y, Akai M, Ide K, et al. Kappa-opioid system in uremic pruritus: multicenter, randomized, double-blind, placebo-controlled clinical studies. J Am Soc Nephrol. 2005;16(12):3742-7.

64 Jaiswal D, Uzans D, Hayden J, Kiberd BA, Tennankore KK. Targeting the opioid pathway for uremic pruritus: a systematic review and meta-analysis. Can J Kidney Health Dis. 2016;3:2054358116675345.

65 Pauli-Magnus C, Mikus G, Alscher DM, Kirschner T, Nagel W, Gugeler N, et al. Naltrexone does not relieve uremic pruritus: results of a randomized, double-blind, placebocontrolled crossover study. J Am Soc Nephrol. 2000;11(3):514-9.

66 Peer G, Kivity S, Agami O, Fireman E, Silverberg D, Blum M, et al. Randomised crossover trial of naltrexone in uraemic pruritus. Lancet. 1996;348(9041):1552-4.

67 Legroux-Crespel E, Clèdes J, Misery L. A comparative study on the effects of naltrexone and loratadine on uremic pruritus. Dermatology. 2004;208(4):326-30.

68 Marquez D, Ramonda C, Lauxmann JE, Romero CA, Vukelic VL, Martinatto C, et al. Uremic pruritus in hemodialysis patients: treatment with desloratidine versus gabapentin. J Bras Nefrol. 2012;34(2):148-52.

69 Shakiba M, Sanadgol H, Azmoude HR, Mashhadi MA, Sharifi H. Effect of sertraline on uremic pruritus improvement in ESRD patients. Int J Nephrol. 2012;2012:363901.

70 Chan KY, Li CW, Wong H, Yip T, Chan ML, Cheng HW, et al. Use of sertraline for antihistamine-refractory uremic pruritus in renal palliative care patients. J Palliat Med. 2013; 16(8):966-70.
71 Pakfetrat M, Malekmakan L, Hashemi N, Tadayon T. Sertraline can reduce uremic pruritus in hemodialysis patient: a double blind randomized clinical trial from Southern Iran. Hemodial Int. 2018;22(1):103-9.

72 Vessal G, Sagheb MM, Shilian S, Jafari P, Samani SM. Effect of oral cromolyn sodium on $\mathrm{CKD}$-associated pruritus and serum tryptase level: a double-blind placebo-controlled study. Nephrol Dial Transplant. 2010;25(5): 1541-7.

73 Najafabadi MM, Faghihi G, Emami A, Monghad M, Moeenzadeh F, Sharif N, et al. Zinc sulphate for relief of pruritus in patients on maintenance hemodialysis. Ther Apher Dial. 2012;16(2):142-5.

74 Omidian M, Khazanee A, Yaghoobi R, Ghorbani AR, Pazyar N, Beladimousavi SS, et al. Therapeutic effect of oral nicotinamide on refractory uremic pruritus: a randomized, double-blind study. Saudi J Kidney Dis Transpl. 2013;24(5):995-9.

75 Yoshimoto-Furuie K, Yoshimoto K, Tanaka T, Saima S, Kikuchi Y, Shay J, et al. Effects of oral supplementation with evening primrose oil for six weeks on plasma essential fatty acids and uremic skin symptoms in hemodialysis patients. Nephron. 1999;81(2):151-9.

76 Mahmudpour M, Roozbeh J, Raiss Jalali GA, Pakfetrat M, Ezzat Zadegan S, Sagheb MM. Therapeutic effect of montelukast for treatment of uremic pruritus in hemodialysis patients. Iran J Kidney Dis. 2017;11(1):50-5.

77 Nasrollahi AR, Miladipour A, Ghanei E, Yavari P, Haghverdi F. Montelukast for treatment of refractory pruritus in patients on hemodialysis. Iran J Kidney Dis. 2007;1(2):73-7.

78 Silva SR, Viana PC, Lugon NV, Hoette M, Ruzany F, Lugon JR. Thalidomide for the treatment of uremic pruritus: a crossover randomized double-blind trial. Nephron. 1994;67(3): 270-3.

79 Pakfetrat M, Basiri F, Malekmakan L, Roozbeh J. Effects of turmeric on uremic pruritus in end stage renal disease patients: a doubleblind randomized clinical trial. J Nephrol. 2014;27(2):203-7.

80 Pojawa-Gołąb M, Jaworecka K, Reich A. NK-1 receptor antagonists and pruritus: review of current literature. Dermatol Ther. 2019;9(3):391-405

81 Kaur R, Sinha VR. Antidepressants as antipruritic agents: a review. Eur Neuropsychopharmacol. 2018;28(3):341-52.

82 Tapia L, Cheigh JS, David DS, Sullivan JF, Saal S, Reidenberg MM, et al. Pruritus in dialysis patients treated with parenteral lidocaine. N Engl J Med. 1977;296(5):261-2.

83 Lubach D, Kock BW. [Treatment of severe pruritus in dialysis patients with selective UVphototherapy (SUP)]. Fortschr Med. 1983; 101(46):2125-8.

84 Gilchrest BA, Rowe JW, Brown RS, Steinman TI, Arndt KA. Ultraviolet phototherapy of uremic pruritus. Long-term results and possible mechanism of action. Ann Intern Med. 1979;91(9):17-21. 
85 Ada S, Seçkin D, Budakoğlu I, Ozdemir FN. Treatment of uremic pruritus with narrowband ultraviolet B phototherapy: an open pilot study. J Am Acad Dermatol. 2005;53(1): 149-51.

86 Blachley JD, Blankenship DM, Menter A, Parker TF 3rd, Knochel JP. Uremic pruritus: skin divalent ion content and response to ultraviolet phototherapy. Am J Kidney Dis. 1985;5(5):237-41.

87 Chen ZJ, Cao G, Tang WX, Lv XY, Huang SM, Qin W, et al. A randomized controlled trial of high-permeability haemodialysis against conventional haemodialysis in the treatment of uraemic pruritus. Clin Exp Dermatol. 2009; 34(6):679-83.

88 Jiang X, Ji F, Chen ZW, Huang QL. Comparison of high-flux hemodialysis with hemodialysis filtration in treatment of uraemic pruritus: a randomized controlled trial. Int Urol Nephrol. 2016;48(9):1533-41.

89 Zhang J, Yuan Y, An X, Ouyang C, Ren H, Yang $\mathrm{G}$, et al. Comparison of combined blood purification techniques in treatment of dialysis patients with uraemic pruritus. Int J Clin Exp Med. 2016;9(5):8563-8.
90 Afshar M, Rebollo-Mesa I, Murphy E, Murtagh FE, Mamode N. Symptom burden and associated factors in renal transplant patients in the U.K. J Pain Symptom Manage. 2012; 44(2):229-38.

$91 \mathrm{Kim} \mathrm{KH}$, Lee MS, Choi SM. Acupuncture for treating uremic pruritus in patients with endstage renal disease: a systematic review. J Pain Symptom Manage. 2010;40(1):117-25.

92 Badiee Aval S, Ravanshad Y, Azarfar A, Mehrad-Majd H, Torabi S, Ravanshad S. A systematic review and meta-analysis of using acupuncture and acupressure for uremic pruritus. Iran J Kidney Dis. 2018;12(2):78-83.

93 Balaskas EV, Bamihas GI, Karamouzis M, Voyiatzis G, Tourkantonis A. Histamine and serotonin in uremic pruritus: effect of ondansetron in CAPD-pruritic patients. Nephron. 1998;78(4):395-402.

94 Ashmore SD, Jones CH, Newstead CG, Daly MJ, Chrystyn H. Ondansetron therapy for uremic pruritus in hemodialysis patients. Am J Kidney Dis. 2000;35(5):827-31.
95 To TH, Clark K, Lam L, Shelby-James T, Currow $\mathrm{DC}$. The role of ondansetron in the management of cholestatic or uremic pruritus: a systematic review. J Pain Symptom Manage. 2012;44(5):725-30.

96 van Leusen R, Kutsch Lojenga JC, Ruben ATh A. Is cholestyramine helpful in uraemic pruritus? Br Med J. 1978;1(6117):918-9.

97 Silverberg DS, Iaina A, Reisin E, Rotzak R, Eliahou HE. Cholestyramine in uraemic pruritus. Br Med J. 1977;1(6063):752-3.

98 Garcia-Borreguero D, Silber MH, Winkelman JW, Högl B, Bainbridge J, Buchfuhrer M, et al. Guidelines for the first-line treatment of restless legs syndrome/Willis-Ekbom disease, prevention and treatment of dopaminergic augmentation: a combined task force of the IRLSSG, EURLSSG, and the RLS-foundation. Sleep Med. 2016;21:1-11.

99 Iqbal Z, Azmi S, Yadav R, Ferdousi M, Kumar $\mathrm{M}$, Cuthbertson DJ, et al. Diabetic peripheral neuropathy: epidemiology, diagnosis, and pharmacotherapy. Clin Ther. 2018;40(6): 828-49. 